\section{ARTICLES OF PROFESSIONAL INTEREST}

\section{Editorial}

\author{
G. L. Sivakumar Babu ${ }^{1}$
}

Published online: 21 August 2015

(c) Indian Geotechnical Society 2015

Dear readers

The July-September Issue of Indian Geotechnical Journal has twelve papers and cover wide spectrum of topics in Geotechnical Engineering.

Madabhushi and Madabhushi from the University of Cambridge UK, presented comprehensive results of finite element analysis of floatation of rectangular tunnels following earthquake induced liquefaction using dynamic finite element analyses. Sinusoidal and more realistic earthquake input motions are considered and the responses are analysed. Results show that, from a design point of view, both tunnel uplift and settlement can be detrimental as movement of individual segments of the tunnels can open gaps between transverse joints of the tunnel that can lead to flooding and a consequent loss of infrastructure. Mukesh Kumar et al. studied the response of semi-buried structures subjected to multiple blast loading considering soil-structure Interaction. Results indicate that the buried depth of structure, soil-structure interaction and strain rate governs the dynamic behaviour of the structure. It is concluded that blast design of structure is governed by the time interval between successive blasts, and not merely by single blast of the given amount of explosive.

Jayalekshmi and Chinmayi examined soil-structure interaction effect on seismic force evaluation of RC framed buildings with various shapes of shear Wall as Per IS 1893 and IBC standards. The study shows the significant effects of SSI in altering the seismic response of structure. It also

\footnotetext{
G. L. Sivakumar Babu

gls@civil.iisc.ernet.in

1 Indian Institute of Science, Bangalore, India
}

shows that the base shear values obtained as per IBC are higher than the values obtained as IS and the corrugated shape of shear wall experiences the lowest base shear compared to cylindrical and rectangular shape shear walls for buildings with aspect ratio below 3 . Vijaya Ravichandran et al. presented results of field testing of suction anchors for mooring applications. Since suction anchors are subjected to cyclic loading in the offshore areas due to effect of waves and winds, tests for static and cyclic pullout were carried out. It is found that anchor geometry, angle of pullout and nature of pull (static/cyclic) have a significant influence on the response to pullout.

$\mathrm{Li}$ and Michel Aubertin presented results of numerical analysis of the stress distribution in symmetrical backfilled trenches with Inclined Walls. Results show that the application of the basic Marston's solution can lead to a significant underestimation of the stresses, particularly in the lower part of a trench. The magnitude of the undervaluation is more pronounced when the stiffness contrast between the backfill and wall material is small. Dan and Sahu presented a simplified approach for estimation of braced wall deflection during excavation in soft clay and the diaphragm wall is assumed as continuous beam. Peck's earth pressure diagram for braced wall is used for load calculation while Terzaghi's equation is considered to derive coefficient of modulus of subgrade reaction. Applicability of the proposed approach is verified by comparing the estimated values of wall de-flection with the measured values of three different case studies.

Abhishek et al. present a method for the estimation of bearing capacity of a strip footing resting on a reinforced foundation bed over soft ground stabilized with a granular trench. The percentage improvement in the bearing capacity of the strip footing due to reinforcement of the soft 
ground with a granular trench coupled with unreinforced and reinforced granular fill is established through the comparisons. Arup Bhattacharjee and Murali Krishna studied the strain behavior of soil and reinforcement in wrap faced reinforced soil walls subjected to seismic excitation. Parametric studies are also conducted to study behavior of soil strain and reinforcement strain for different reinforcement configurations and backfill materials. The implications are discussed.

Anbazhagan presented an integrated approach in subsurface investigation of the existing geotechnical structure using ground penetrating radar (GPR), seismic survey and by drilling a limited number of boreholes and demonstrate its usefulness in identifying the possible reasons for mis alignment of reinforced earth retaining wall as well as backfill quality. Dhawan and Muralidhar studied the relationship between static moduli and two types of dynamic moduli for different rocks based on a number of tests. Muduli et al. present the development of predictive models of lateral load capacity of pile in clay using artificial intelligence techniques; genetic programming and multivariate adaptive regression spline. Model equations are presented and are found to be more compact compared to ANN and SVM models. A sensitivity analysis is made to identify the important inputs contributing to the lateral load capacity of pile. Jayasree et al. studied the shrinkage characteristics of expansive soil treated with coir waste and noted that three dimensional shrinkage strain test is more reliable for computing the volumetric shrinkage than shrinkage limit test. I wish members of the geotechnical community happy reading. 